\title{
Efecto in vitro de preparados con levaduras sobre la producción de metano ruminal
}

\author{
In vitro effect of yeast preparations on ruminal \\ methane production
}

Fecha recepción: 28 de marzo de 2014

Fecha Aprobación: 12 de mayo de 2014

\author{
Byron Leoncio Díaz-Monroy ${ }^{1}$, \\ Sandra Isabel Castañeda-Caguana ${ }^{2}$
}

\section{Resumen}

El objetivo de este trabajo fue evaluar el efecto, in vitro, de preparados con levaduras Saccharomyces cerevisiae y Levica - 25 viables sobre los metanógenos y la metanogénesis ruminal. Se compararon 3 tratamientos: C) Cynodon nlemfuensis (Pasto estrella), como control; S) Cynodon nlemfuensis + Saccharomyces cerevisiae, y L) Cynodon nlemfuensis + Levica 25, todos con líquido ruminal de búfalo adulto macho, y se valoraron mediante técnicas estándares de laboratorio indicadores microbiológicos y fermentativos a las 8,12 y 24 horas de fermentación, bajo diseño completamente aleatorizado en arreglo bifactorial $3 \times 3$ (3 tratamientos con 3 horarios de muestreo), con 4 repeticiones para cada tratamiento, en total 36 unidades experimentales representadas por botellas de vidrio de $100 \mathrm{~mL}$ cada una. Existieron diferencias estadísticas $(P \leq 0.01)$ entre tratamientos y entre horarios evaluados para los siguientes indicadores: población de metanógenos, producción de gas metano, bacterias celulolíticas, bacterias viables totales, protozoos y $\mathrm{pH}$. La utilización de levaduras como suplemento en la dieta de rumiantes mejora el aprovechamiento del alimento, con

\begin{abstract}
The aim of this study was to evaluate the effect, in vitro, of Saccharomyces cerevisiae and Levica -25 preparations, viables on ruminal methanogens and methanogenesis. Three treatments were compared: C) Cynodon nlemfuensis (Star grass) as control; S) C. nlemfuensis + S. cerevisiae; and L) Levica 25 + C. nlemfuensis, all with rumen fluid from adult male buffalo. The treatments were evaluated using standard laboratory techniques for microbiological and fermentation indicators at 8,12 and 24 hours of fermentation, under completely randomized design with $3 \times 3$ bifactorial arrangement ( 3 treatments with 3 sampling times), with 4 replicates for each treatment, and a total of 36 experimental units represented by glass bottles of $100 \mathrm{~mL}$ each. We observed statistical differences $(P \leq 0.01)$ between treatments and between times assessed for the following indicators: methanogens population, methane gas production, cellulolytic bacteria, total viable bacteria, protozoa and $\mathrm{pH}$. Yeast as a supplement in ruminants diet improves the food usage, increasing the cellulolytic bacteria population and decreasing the methanogenic bacteria population and enteric gas, which is an
\end{abstract}

1 Ph. D. Escuela Superior Politécnica de Chimborazo (Riobamba, Ecuador). bdiaz@espoch.edu.ec.

2 Escuela Superior Politécnica de Chimborazo (Riobamba, Ecuador). 
incremento de la población de bacterias celulolíticas y disminución de la población de bacterias metanogénicas y gas entérico, lo cual es un aporte interesante a la mitigación de la contaminación ambiental. La levadura Levica-25 resultó más eficiente. Se recomienda utilizar preparados de Saccharomyces cerevisiae y Levica 25 en rumiantes mayores para disminuir la metanogénesis en el rumen e incrementar la población de bacterias celulolíticas.

Palabras clave: Celulolítico, Levadura, Metanogénesis, Metanógeno, Ruminal. interesting contribution for mitigation environmental pollution. The yeast Levica -25 was more efficient. We recommend using Saccharomyces cerevisiae and Levica -25 preparations in large ruminants to decrease methanogenesis in the rumen and increase the population of cellulolytic bacteria.

Keywords: Cellulolytic, Yeast, Methanogenesis, Methanogenic, Ruminal. 


\section{Introducción}

Los rumiantes producen alrededor del $97 \%$ del metano generado por los animales domésticos; lo hacen en su rumen, como consecuencia inevitable de la fermentación microbiana de los carbohidratos ingeridos en la dieta; en rumiantes adultos se estima una producción de 300-600 L.dia $^{-1}$ de metano(1).

El metano producido por los rumiantes es el responsable del $18 \%$ del efecto invernadero producido en el planeta (2); se emite mediante el eructo, y la cantidad que se libera depende del volumen y del tipo de alimento que consumen los rumiantes, siendo su producción menor cuando las dietas tienen bajas cantidades de fibra (3).

El metano que emiten los rumiantes no solo constituye un problema ecológico, también contribuye a la pérdida de energía del alimento, lo que trae como consecuencia una disminución de la productividad de los animales; se estima que más del 10\% de la energía bruta que contienen los alimentos se pierde en forma de metano (4).

Se ha demostrado en rumiantes que las prácticas de alimentación que aumenten el consumo y la velocidad de digestión, o acorten el tiempo de permanencia de los alimentos en el rumen, disminuyen la producción de metano por unidad de forraje digerido. Al respecto, el empleo de preparados microbianos con levaduras viables constituye una atractiva opción; una posibilidad estudiada para reducir la producción de metano en el rumen: el empleo de aditivos con levadura Saccharomyces cerevisiae (5), determinó que esta levadura es capaz de activar la población microbiana ruminal, e indicó que otras levaduras, entre las que se destaca Levica 25, pueden producir potencialmente efectos superiores a la Saccharomyces cerevisiae. Es bien reconocido que la dieta y, principalmente, el contenido de fibra influyen en la densidad poblacional de metanógenos en el rumen; así, menor cantidad de bacterias metanogénicas se detectarán en el rumen de animales alimentados con concentrado, en relación a los alimentados con forraje (6).

El empleo de aditivos microbianos con levaduras viables es una opción válida para contrarrestar la población de metanógenos debido al importante papel de estas como manipuladoras de la fermentación ruminal, lo que provoca incremento de bacterias celulolíticas que permiten mejor digestión $y$, consecuentemente, mayor aprovechamiento de los nutrientes del alimento. Por estas consideraciones, en la presente investigación se planteó evaluar el efecto de preparados de levaduras a partir de Saccharomyces cerevisiae y LEVICA 25 sobre la metanogénesis ruminal in vitro de rumiantes mayores.

\section{Materiales y Métodos}

Localización y duración del experimento. Se realizaron dos experimentos similares: el primero en el Laboratorio de Microbiología del Rumen, del Instituto de Ciencia Animal, Cuba, y el segundo, llamado también de validación, en el Laboratorio de Biotecnología y Microbiología Animal, de la Escuela Superior Politécnica de Chimborazo, Ecuador. En los dos trabajos se aplicó la misma metodología: diseño experimental y análisis estadístico; al final se obtuvieron iguales resultados.

Unidades experimentales. Las unidades experimentales estuvieron conformadas por 36 botellas de vidrio de $100 \mathrm{~mL}$ cada una, previamente esterilizadas en autoclave a 121 ${ }^{\circ} \mathrm{C}$, durante $15 \mathrm{~min}$ a 2 atmósferas de presión y selladas con tapón de butilo y agrafe, resultantes de los 3 tratamientos con 3 horarios de muestreo cada uno y con 4 repeticiones $(3 \times 3 \times 4=36)$, en las cuales se introdujo el líquido ruminal, pasto estrella (Cynodon nlemfuensis) y los preparados de levaduras, ya sea de Saccharomyces o Levica 25, según el tratamiento que corresponda.

Análisis estadísticos y pruebas de significancia. Los resultados experimentales fueron sometidos a los siguientes procedimientos:

- Análisis de varianza (ADEVA)

- Separación de medias por el método de rango múltiple de Duncan $(P<0.01)$

Procedimiento experimental. El experimento se condujo bajo condiciones in vitro, para lo cual se utilizó la técnica de (7) y se utilizaron botellas de vidrio de $100 \mathrm{~mL}$, selladas con tapón de butilo y agrafe. En cada botella se introdujo la mezcla integrada por líquido de rumen y solución buffer en una relación de una parte de líquido ruminal 
con tres partes de solución buffer, y para el control se introdujo la mezcla integrada por líquido de rumen y solución buffer en una relación de una parte de líquido ruminal con cuatro partes de solución buffer.

El inóculo ruminal se obtuvo a partir de dos búfalos canulados en rumen alimentados con una dieta de forraje de gramíneas sin suplementación adicional y libre acceso al agua.

La muestra de líquido ruminal se colectó a través de la cánula, con la ayuda de una bomba de vacío, y se conservó en termos herméticamente cerrados hasta su traslado al Laboratorio de microbiología del rumen del Instituto de Ciencia Animal, donde posteriormente se filtraron a través de muselina. Para conformar la mezcla a fermentar se utilizó el licuado de líquido ruminal de los búfalos, con el propósito de eliminar el efecto animal.

Técnicas de cultivo y conteos de microorganismos. Se utilizó la técnica de cultivo de (8), en tubos roll y bajo condiciones de anaerobiosis estricta. La siembra de bacterias viables totales y celulolíticas se efectuó en los medios de cultivo de (9) y modificado (10). Las bacterias metanogénicas se contaron por el mismo método, pero se utilizó una mezcla de hidrógeno y dióxido de carbono (60:40) en la fase gaseosa.

Los protozoos se preservaron en formol al $10 \%$ en una dilución 1:1 (v/v). Las muestras preservadas se guardaron en refrigerador a $4{ }^{\circ} \mathrm{C}$ y se contaron posteriormente al microscopio óptico en cámara de Neubauer. Para ello, los protozoos se tiñeron con una solución de violeta de genciana al $0.01 \%$ en ácido acético glacial al 1\%.

Preparación de la muestra del pasto. El alimento base para la fermentación es Cynodon nlemfuensis (pasto estrella), el cual se obtuvo a partir de un área sin pastorear del Instituto de Ciencia Animal. Para su preparación se recolectaron hojas con sus pecíolos, de manera que semeje el bocado del animal. La muestra se secó en estufa a $60{ }^{\circ} \mathrm{C}$ durante 48 horas. Luego se molió en molino hasta un tamaño de partículas de $1 \mathrm{~mm}$. Se determinó su composición química según AOAC (1995), obteniéndose en porcentaje: 7,$26 ; 74,57 ; 10,11$; 0,42 y 0,18 de PB, FDN, ceniza, calcio y fósforo, respectivamente. Se conservó en frascos de cristal hasta su posterior utilización en el experimento.

Obtención del preparado microbiano con Saccharomyces cerevisiae y Levica 25. Primero se prepararon sendos preinóculos, para lo cual se toman varias asas de cultivos en cuña de ambas levaduras con 24 horas de crecimiento y se disuelven en $10 \mathrm{~mL}$ de caldo extracto de malta. Se incuba a $30^{\circ} \mathrm{C}$ durante 16 horas. El preparado que se utilizó en el experimento se obtuvo después de inocular los $10 \mathrm{~mL}$ anteriormente obtenidos en $100 \mathrm{~mL}$ de caldo extracto de malta. De igual manera, se colocaron en la incubadora a $30^{\circ} \mathrm{C}$ durante 16 horas. Se obtuvieron dos preparados microbianos, que corresponden a levaduras con una concentración inicial de células de $1 \times 10^{7}$ cel. $\mathrm{mL}^{-1}$.

La formulación del material de fermentación para $100 \mathrm{~mL}$ fue: líquido ruminal, $20 \mathrm{~mL}$; solución amortiguadora, $60 \mathrm{~mL}$, y preparado con levaduras, $20 \mathrm{~mL}$; a este líquido se añadió $1 \mathrm{~g}$ de material vegetal (Pasto estrella triturado y seco); se evaluaron los diferentes indicadores fermentativos y microbiológicos a las 8,12 y $24 \mathrm{~h}$ de fermentación.

\section{Resultados y Discusión}

Evaluación de la metanogénesis ruminal in vitro por efecto de preparados microbianos con levaduras viables

Potencial hidrógeno $(\mathbf{p H})$. Se registraron diferencias estadísticas entre tratamientos, no así para el horario de fermentación. En cuanto al $\mathrm{pH}$ del líquido ruminal al utilizar levaduras in vitro versus el tratamiento control, se puede señalar que el pH más bajo se presentó con la utilización de la levadura Levica 25, mientras que al utilizar Saccharomyces cerevisiae el $\mathrm{pH}$ fue mayor; finalmente, con el tratamiento control se presentó un pH alcalino, siendo este el más elevado en comparación con el pH obtenido en los tratamientos en los que se utilizó levaduras (Cuadro 1). El uso de algunas cepas de $S$. cerevisiae puede aumentar el $\mathrm{pH}$ ruminal (11). 
Cuadro 1. Evaluación del pH, por efecto de preparados microbianos con levaduras viables sobre la metanogénesis ruminal "in vitro", de acuerdo con el tratamiento y el tiempo de fermentación.

\begin{tabular}{|c|c|c|c|c|c|c|}
\hline \multirow[b]{2}{*}{ INDICADOR } & \multicolumn{3}{|c|}{ TRATAMIENTOS } & - & \multirow[b]{2}{*}{ Prob. } & \multirow[b]{2}{*}{ CV (\%) } \\
\hline & C & $\mathbf{S}$ & L & X & & \\
\hline $\mathrm{pH}$ & $7,43 \mathrm{a}$ & $6,79 \mathrm{~b}$ & $6,33 \mathrm{C}$ & 6,85 & 0,0001 & 5,47 \\
\hline
\end{tabular}

C: Control, S: Saccharomyces cerevisiae, L: Levica 25

\begin{tabular}{|c|c|c|c|c|c|c|}
\hline \multirow[b]{2}{*}{ INDICADOR } & \multicolumn{3}{|c|}{ HORAS DE FERMENTACIÓN } & - & \multirow[b]{2}{*}{ Prob. } & \multirow[b]{2}{*}{ CV $(\%)$} \\
\hline & 8 & 12 & 24 & $\mathbf{X}$ & & \\
\hline $\mathrm{pH}$ & $6,98 \mathrm{a}$ & $6,81 \mathrm{a}$ & $6,77 \mathrm{a}$ & 6,85 & 0,3632 & 5,47 \\
\hline
\end{tabular}

Producción de gas total $\left(\mathrm{mL}^{\mathrm{g}} \mathrm{g}^{-1}\right)$. Mediante la incorporación in vitro de Levica 25 se determinaron diferencias estadísticas $(P \leq 0,01)$, es así como a las 24 horas de evaluación se determinó el mayor promedio de gas total, seguido en su orden por las producciones determinadas a las 12 y $8 \mathrm{~h}$ de evaluación (Cuadro 2).

Los resultados obtenidos en cada una de las horas evaluadas en los diferentes tratamientos demuestran la marcada disminución de gas metano, que compone gran parte de la producción de gas total, considerando lo expuesto por (5), quienes determinaron que esta levadura es capaz de activar la población microbiana ruminal y reducir la producción de Metano, destacando a LEVICA 25, que puede producir potencialmente efectos superiores a la Saccharomyces cerevisiae, por lo que en la presente investigación se obtuvieron efectos similares a los expuestos por el mencionado autor.

En otro trabajoy en similares esfuerzos por disminuir las emisiones de gas ruminal a la atmósfera, (12) reportó que al utilizar aceite esencial de orégano en dosis de 25 a 100 ppm, sobre la fermentación ruminal, disminuye la producción de gas entérico, efecto atribuido a la acción antimicrobial del Timol, principal componente de este aceite.

Producción de gas metano $(\boldsymbol{\mu L})$. Se determinaron diferencias estadísticas $(\mathrm{P} \leq 0,01)$ para los promedios de producción de gas metano entre tratamientos y entre horarios de fermentación, con diferentes comportamientos para cada tipo de levadura evaluada; de esta manera, al comparar la producción de metano dentro del grupo control, se determinó el mayor promedio a las 24 horas, seguido por producciones más bajas de gas metano a las 12 y 8 horas de evaluación (Cuadro 2). El comportamiento in vitro de Levica 25 para este indicador difirió estadísticamente $(\mathrm{P} \leq 0,01)$ de los demás tratamientos, es así como a las 24 horas de evaluación se determinó el promedio más bajo de producción de metano, con mayores valores para las 12 y 8 horas de evaluación (Cuadro 2). Los resultados obtenidos con los preparados microbianos se relacionan con lo descrito por (8), quien informó que los metanógenos que viven en el interior o adheridos a la superficie de los protozoos ciliados del rumen son responsables de más del $37 \%$ de las emisiones de metano. Además, (13) mencionaron que las bacterias anaerobias metanógenas son las responsables de la producción de metano; estas utilizan diferentes sustratos, pero los principales son el $\mathrm{H}_{2}$ y el $\mathrm{CO}_{2}$. La eliminación de estos gases, principalmente dél $\mathrm{H}_{2}$, garantiza la estabilidad del $\mathrm{pH}$, lo que favorece una óptima fermentación ruminal.

La suplementación de la dieta con lípidos ricos en ácidos grasos insaturados también reduce las emisiones de metano a través de la hidrogenación de ellos (14). 
Cuadro 2. Evaluación de las características microbiológicas, bajo el efecto de preparados con levaduras viables sobre la metanogénesis ruminal "in vitro", de acuerdo al tratamiento y tiempo de fermentación.

\begin{tabular}{|c|c|c|c|c|c|c|c|c|c|c|c|c|}
\hline \multirow[b]{3}{*}{ VARIABLES } & \multicolumn{9}{|c|}{$\begin{array}{l}\text { TRATAMIENTOS DE ACUERDO AL TIEMPO } \\
\end{array}$} & \multirow[b]{3}{*}{$\mathrm{X}$} & \multirow[b]{3}{*}{ Prob. } & \multirow[b]{3}{*}{ CV $(\%)$} \\
\hline & \multicolumn{3}{|c|}{8 Horas } & \multicolumn{3}{|c|}{12 Horas } & \multicolumn{3}{|c|}{24 Horas } & & & \\
\hline & C & $\mathrm{S}$ & L & C & 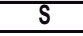 & L & C & 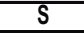 & L & & & \\
\hline Densidad de Bacterias Viables Totales, $1 \times 10^{11} \mathrm{UFC} / \mathrm{mL}$ & $72,00 \mathrm{a}$ & $66,00 \mathrm{~b}$ & $18,00 \mathrm{c}$ & $112,95 \mathrm{a}$ & $78,50 \mathrm{~b}$ & $69,50 \mathrm{c}$ & $264,25 \mathrm{a}$ & $169,50 \mathrm{~b}$ & $126,0 \mathrm{c}$ & 108,52 & $0.0001^{1 *}$ & 1,43 \\
\hline Densidad de Bacterias Celulolíticas, 1×10 UFC/mL & $26,00 \mathrm{c}$ & $27,00 \mathrm{~b}$ & $30,00 \mathrm{a}$ & $14,00 \mathrm{c}$ & $30,00 \mathrm{~b}$ & $42,50 \mathrm{a}$ & $13,50 \mathrm{c}$ & $37,25 b$ & $64,50 \mathrm{a}$ & 31,64 & $0.0001^{\text {** }}$ & 3,32 \\
\hline Densidad de Bacterias Metanogénicas, $1 \times 10^{9} \mathrm{UFC} / \mathrm{mL}$ & $81,00 \mathrm{a}$ & $72,50 \mathrm{~b}$ & $66,53 \mathrm{c}$ & $112,00 \mathrm{a}$ & $54,53 \mathrm{~b}$ & $43,03 \mathrm{c}$ & $300,00 \mathrm{a}$ & $48,48 \mathrm{~b}$ & $39,25 \mathrm{c}$ & 90,81 & $0.0001^{* *}$ & 2,25 \\
\hline Densidad de Protozoarios, $1 \times 10^{5}$ especimenes $/ \mathrm{mL}$ & 19,13 a & $16,50 \mathrm{~b}$ & $14,88 \mathrm{c}$ & $21,50 \mathrm{a}$ & $14,50 \mathrm{~b}$ & $12,63 \mathrm{c}$ & 34,88 a & $11,25 b$ & $6,88 \mathrm{c}$ & 16,90 & $0.0001^{\text {** }}$ & 6,61 \\
\hline Producción de Gas Total, mL/g de MS & $43,30 \mathrm{a}$ & $30,30 \mathrm{~b}$ & $20,50 \mathrm{c}$ & $62,13 \mathrm{a}$ & $45,50 \mathrm{~b}$ & $25,33 \mathrm{c}$ & $95,00 \mathrm{a}$ & $71,55 \mathrm{~b}$ & $42,55 \mathrm{c}$ & 48,46 & $0.0001^{* *}$ & 3,41 \\
\hline Producción de Gas Metano, $\mu \mathrm{L}$ & 9,25 a & $8,25 \mathrm{~b}$ & $6,75 \mathrm{c}$ & $10,50 \mathrm{a}$ & $7,75 b$ & $4,50 \mathrm{c}$ & $11,50 \mathrm{a}$ & $4,75 b$ & $3,00 \mathrm{c}$ & 7,36 & $0.0001^{\text {** }}$ & 6,60 \\
\hline
\end{tabular}

\section{C: Control SS: Saccharomyces cerevisiae L: Levica 25}

Letras iguales no difieren estadísticamente. Según Duncan $(\mathrm{P}<0.01)$. Prob: Probabilidad. CV $(\%)$ :

Porcentaje de Coeficiente de Variación. **: Diferencia altamente significativa entre medias. *:

Diferencia significativa entre medias. ns: No significativa

Cuadro 3. Evaluación de las características fermentativas, bajo el efecto de preparados con levaduras viables sobre la metanogénesis ruminal "in vitro", de acuerdo con el tratamiento y tiempo de fermentación.

\begin{tabular}{|c|c|c|c|c|c|c|c|c|c|c|c|c|}
\hline \multirow[b]{3}{*}{ VARIABLES } & \multicolumn{9}{|c|}{ TIEMPO DE FERMENTACIÓN DE ACUERDO AL TRATAMIENTO } & \multirow[b]{3}{*}{$\mathrm{X}$} & \multirow[b]{3}{*}{ Prob. } & \multirow[b]{3}{*}{$\mathrm{CV}(\%)$} \\
\hline & \multicolumn{3}{|c|}{ Control } & \multicolumn{3}{|c|}{ Saccharomyces cerevisiae } & \multicolumn{3}{|c|}{ Levica 25} & & & \\
\hline & 8 & 12 & 24 & 8 & 12 & 24 & 8 & 12 & 24 & & & \\
\hline Densidad de Bacterias Viables Totales, $1 \times 10^{11} \mathrm{UFC} / \mathrm{mL}$ & $72,00 \mathrm{c}$ & $112,95 b$ & $264,25 \mathrm{a}$ & $66,00 \mathrm{c}$ & $78,50 \mathrm{~b}$ & $169,50 \mathrm{a}$ & $18,00 \mathrm{c}$ & $69,50 \mathrm{~b}$ & $126,00 \mathrm{a}$ & 108,52 & $0.0001^{* *}$ & 1,43 \\
\hline Densidad de Bacterias Celuloliticas, $1 \times 10^{4} \mathrm{UFC} / \mathrm{mL}$ & $26,00 \mathrm{a}$ & $14,00 \mathrm{~b}$ & $13,50 \mathrm{~b}$ & $27,00 \mathrm{c}$ & $30,00 \mathrm{~b}$ & 37,25 a & $30,00 \mathrm{c}$ & $42,50 \mathrm{~b}$ & $64,50 \mathrm{a}$ & 31,64 & $0.0001^{\text {** }}$ & 3,32 \\
\hline Densidad de Bacterias Metanogénicas, $1 \times 10^{9} \mathrm{UFC} / \mathrm{mL}$ & $81,00 \mathrm{c}$ & $112,00 \mathrm{~b}$ & $300,00 \mathrm{a}$ & $72,50 \mathrm{a}$ & $54,53 \mathrm{~b}$ & $48,48 \mathrm{c}$ & $66,53 a$ & $43,03 b$ & $39,25 \mathrm{c}$ & 90,81 & $0.0001^{\text {** }}$ & 2,25 \\
\hline Densidad de Protozoarios, $1 \times 10^{5}$ especimenes $/ \mathrm{mL}$ & $19,13 \mathrm{c}$ & $21,50 \mathrm{~b}$ & 34,88 a & $16,50 \mathrm{a}$ & $14,50 \mathrm{~b}$ & $11,25 c$ & $14,88 \mathrm{a}$ & $12,63 b$ & $6,88 \mathrm{c}$ & 16,90 & $0,0128^{*}$ & 6,61 \\
\hline Producción de Gas Total, mL/g de MS & $43,30 \mathrm{c}$ & $62,13 b$ & $95,00 \mathrm{a}$ & $30,30 \mathrm{c}$ & $45,50 \mathrm{~b}$ & $71,55 \mathrm{a}$ & $20,50 \mathrm{c}$ & $25,33 b$ & 42,55 a & 48,46 & $0.0001^{\text {** }}$ & 3,41 \\
\hline Producción de Gas Metano, $\mu \mathrm{L}$ & $9,25 c$ & $10,50 \mathrm{~b}$ & $11,50 \mathrm{a}$ & $8,25 \mathrm{a}$ & $7,75 \mathrm{a}$ & $4,75 b$ & $6,75 a$ & $4,50 \mathrm{~b}$ & $3,00 \mathrm{c}$ & 7,36 & $0.0006^{* *}$ & 6,60 \\
\hline
\end{tabular}

C: Control SS: Saccharomyces cerevisiae

L: Levica 25 Letras iguales no difieren estadísticamente. Según Duncan $(\mathrm{P}<0.01)$. Prob: Probabilidad. CV $(\%)$ : Porcentaje de Coeficiente de Variación. **: Diferencia altamente significativa entre medias. *: Diferencia significativa entre medias. ns: No significativa

Efecto de preparados microbianos con levaduras viables en la población microbiana ruminal in vitro

Población de bacterias viables totales (UFC. $\mathrm{mL}^{-1}$ ). Mediante la incorporación in vitro de Levica 25 se determinaron diferencias estadísticas $(P \leq 0,01)$ con los demás tratamientos; es así como a las 24 horas de evaluación se determinó el mayor promedio de bacterias viables totales (UFC. $\mathrm{mL}^{-1}$ ), seguido por las densidades de bacterias obtenidas a las 12 y 8 horas de evaluación (Cuadro 3).

Los resultados obtenidos en la población de bacterias viables totales están relacionados con los obtenidos por (15), que al evaluar el efecto de Saccharomyces boulardii en el metabolismo ruminal concluyó que la levadura era digerida por los microorganismos del rumen, por lo que era más utilizada como prebiótico que como aditivo microbiano, por obtener un incremento significativo en la población de bacterias benéficas que favorecían la digestión de los forrajes; similares resultados reportó (16).

Población de bacterias celulolíticas (UFC. $\mathrm{mL}^{-1}$ ). Mediante la incorporación in vitro de Levica 25 se determinaron diferencias estadísticas $(P \leq 0,01)$ con los demás tratamientos; es así como a las 24 horas de evaluación se obtuvo el mayor promedio 
de bacterias celulolíticas (UFC. $\mathrm{mL}^{-1}$ ), seguido por densidades más bajas de bacterias obtenidas a las 12 y 8 horas de evaluación (Cuadro 3).

Respecto a estos resultados, se confirma que la levadura LEVICA 25 resultó ser la más promisoria para su empleo como activadora de la fermentación ruminal celulolítica, lo que coincide con los resultados expuestos por (5), quien afirma que esta cepa produjo $15 \%$ menos de gas en fermentaciones in vitro con Cynodon nlemfuensis, en relación con el resto de las aisladas en el rumen, y además ejerció efectos activadores más prolongados en las poblaciones fúngicas y de bacterias totales y celulolíticas cuando se comparó con la cepa Saccharomyces cerevisiae L/25-7-13, en vacas que consumen dietas fibrosas. Al evaluar el efecto de levaduras viables en la población de bacterias celulolíticas en animales con dietas fibrosas de baja calidad, se encontraron resultados similares (17); lo cual también fue reportado por (18).

Población de bacterias metanogénicas (UFC. $\mathrm{mL}^{-1}$ ). Mediante la incorporación in vitro de Levica 25 se determinaron diferencias estadísticas $(P \leq 0,01)$ con los demás tratamientos, es así como a las 8 horas de evaluación se obtuvo el mayor promedio de bacterias metanogénicas (UFC. $\mathrm{mL}^{-1}$ ), seguido por el promedio obtenido a las 12 horas de evaluación, y finalmente un valor menor se registró a las 24 horas (Cuadro 3), demostrándose el efecto positivo del tratamiento sobre este indicador.

Al respecto, muchos investigadores en el mundo desarrollan estrategias encaminadas a reducir la producción de metano, para lo cual es necesario reducir la población del dominio Archaea, que son los metanógenos ruminales (19) y (14), para ello se utilizan antibióticos, halógenos de metano, productos químicos y lípidos; sin embargo, en la última década se han demostrado las potencialidades de ciertos árboles y arbustos tropicales para reducir la producción de metano (20).

Población de protozoos (especímenes.mL-1). Al comparar los promedios de la densidad de protozoarios, en función del tipo de levadura dentro de cada hora de evaluación, se determinaron diferentes comportamientos dentro de cada uno; así, la densidad de protozoarios dentro del grupo control fue mayor a las 24 horas, con densidades más bajas a las 12 y 8 horas de evaluación (Cuadro 3).

El uso in vitro de Levica 25 determinó diferencias estadísticas $(P \leq 0,01)$ con los demás tratamientos, es así como a las 8 horas de evaluación se obtuvo el mayor promedio de especímenes de protozoarios por $\mathrm{mL}$, seguido por los promedios obtenidos a las 12 y 24 horas de evaluación (Cuadro 3).

De la misma manera, al validar el efecto del preparado microbiano a partir de Saccharomyces cerevisiae, en Ecuador, se determinó que la densidad de protozoarios decrece en relación con el incremento del tiempo de fermentación; así, se ha determinado una disminución en la población de protozoarios a partir de la hora 8, decreciendo progresivamente hasta las horas 12 y 24 de fermentación (Cuadro 4). Al respecto, (21) mencionó que los protozoos son microorganismos que tienen gran importancia, ya que son capaces de fermentar los azúcares y almidones en el rumen; además, muchos de ellos son celulolíticos; sin embargo, su alta presencia en el rumen de animales que consumen dietas fibrosas de baja calidad no es conveniente, ya que compiten con el resto de los microorganismos por los principios nutritivos, tienen altos requerimientos de nitrógeno y pudieran empeorar la situación nutricional de los animales.

Dado que los metanógenos sostienen una relación simbiótica con los protozoos del rumen (22), cualquier factor exógeno que sea capaz de disminuir la población de protozoos reducirá los metanógenos y, consecuentemente, la producción de metano.

Además, (23) sostiene que la reducción de la población protozoaria propicia el incremento en la población de microorganismos celulolíticos, la estabilización del $\mathrm{pH}$ del rumen, el decrecimiento del nivel de amoníaco libre, la reducción de la metanogénesis y el incremento de la eficiencia de utilización digestiva de diferentes dietas, fundamentalmente las fibrosas.

Por otro lado, y en uno de estos intentos de reducir la población de protozoarios del rumen, (24) informó que una dieta para rumiantes con el follaje de Samanea saman y de Albizia lebbeck reduce los citados grupos microbianos. 
Cuadro 4. Validación del efecto de preparados microbianos a base de saccharomyces cerevisiae sobre la población microbiana ruminal in vitro.

\begin{tabular}{lccc}
\hline \multirow{2}{*}{ VARIABLES } & \multicolumn{3}{c}{ HORAS DE EVALUACIÓN } \\
\cline { 2 - 4 } & $\mathbf{8}$ & $\mathbf{1 2}$ & $\mathbf{2 4}$ \\
\hline Densidad de Bacterias Viables Totales, $1 \times 10^{11} \mathrm{UFC} / \mathrm{mL}$ & 65,00 & 74,80 & 158,50 \\
Densidad de Protozoarios, $1 \times 10^{5}$ especímenes/mL & 12,25 & 10,50 & 8,00 \\
Ph & 6,80 & 6,76 & 6,25 \\
\hline
\end{tabular}

$(\mathrm{P} \leq 0,01)$

\section{Conclusiones}

Con base en los resultados obtenidos se concluye lo siguiente que el uso de Levica 25 produce mayor efecto en la reducción de gas total y metano ruminal in vitro durante la digestión de pasto estrella.

La aplicación de preparados microbianos a base de Levica 25 en la digestibilidad in vitro de líquido ruminal determina una menor población de protozoos y bacterias metanogénicas, favoreciendo el desarrollo de bacterias celulolíticas en el rumen.

En la validación realizada en Ecuador se determinó que la utilización en bovinos de un preparado microbiano a base de Saccharomyces cerevisiae presenta resultados similares a los obtenidos en Cuba.

\section{Recomendaciones}

Utilizar preparados microbianos a partir de levaduras (Saccharomyces cerevisiae y Levica 25) en rumiantes mayores para disminuir la metanogénesis en el rumen e incrementar la población de bacterias celulolíticas que permitirán una mayor digestibilidad y aprovechamiento de los nutrientes de los pastos.

Realizar investigaciones para evaluar los niveles adecuados de suministro de preparados microbianos a base de levaduras en bovinos lecheros y de carne.

\section{Referencias}

(1) Johnson D.E., Johnson K.A., Ward G.M. \& Branine M.E. Ruminants and other animals. Chapter 8. En: Atmospheric Methane: Its Role in the Global Environment. Eds. M.A.K. Khalil,
Springer-Verlag, Berlin Heidelberg. Germany. 2000.

(2) Beauchemin K.A. \& McGinn S.M. Methane emissions from feedlot cattle fed barley or corn diets. J. Anim. Sci., 2005; 83: 653.

(3) Gil S.B. Sistema de producción de carne bovina: Engorde intensivo. Elementos que intervienen y posibles impactos en el medio ambiente. Buenos Aires, Argentina, 2004.

(4) Anderson R.C., Callaway T.R., van Kessel J.A.S., Jung Y.S., Edrington T.S. \& Nisbet D.J. Effect of select nitro compounds on ruminal fermentation; an initial look at their potential to reduce economic and environmental costs associated with ruminal methanogenesis. Bioresource Technol, 2003; 90: 59.

(5) Marrero Y. Las levaduras como mejoradoras de la fermentación ruminal de dietas con alto contenido de fibra. Tesis de Doctorado en Ciencias Veterinarias. Instituto de Ciencia Animal. La Habana. Cuba, 2005.

(6) Demeyer D.L. \& fievez V. Ruminants et environnement: la méthanogenèse. Ann. Zootech, 2000; 49: 95.

(7) Theodorou M.K, Williams B.A., Dhanoa M.S., Mcallan A.B. \& France J. A simple gas production method using a pressure transducer to determine the fermentation kinetics of ruminants feed. Anim. Feed. Sci. Tech, 1994; 48: 185.

(8) Hungate R. G. The anaerobic, mesophilic cellulolitic bacteria. Bacterial, 1970; 112.

(9) Caldwell D. R. \& Bryant M.P. Medium without fluid for non selective enumeration and isolation of rumen bacteria. Appl. Microbiol, 1966; 1134.

(10)Galindo J. Efecto de la zeolita en la población de bacterias celulolíticas y su actividad en vacas que consumen ensilaje. Tesis Ph.D. Instituto de Ciencia Animal, La Habana, Cuba, 1988.

(11)Kamra D.N., Chaudhary L.C., Neeta-Agarwal, Singh R., Pathak N.N. \& Agarwal N. Growth performance, nutrient utilization, rumen 
fermentation and enzyme activities in calves fed on Saccharomyces cerevisiae supplemented Diet. Indian-J. Animal-Sci., 2002; 72: 472.

(12) Rodríguez T. Estudio del efecto del aceite esencial de orégano de monte (Lippia origanoides) del Alto Patía sobre la metanogénesis y la actividad fibrolítica del ecosistema ruminal. Tesis Doctoral. Universidad Nacional de Colombia. Bogotá. 2014.

(13) Thauer R. K. \& Shima S. Biogeochemistry: Methane and microbes, Nature, 2006; 440: 878.

(14) Beauchemin K.A. Kreuzer M., Mara O. \& McAllister. Nutritional management for enteric methane abatement's review. Australian J. Experimental Agric., 2008; 48: 21.

(15) Orpin C. The role of ciliate protozoa and fungi in the rumen digestion of plant cell walls. Anim. Feed Sci. Technol, 1983; 10: 121-143.

(16) Dawson K.A. \& Girard I.D. Biochemical and physiological basis for the stimulatory effects of yeast preperations on ruminal bacteria. En: Biotechnology in the Feed Industry. Eds. T.P. Lyons \& K.A. Jacques. Nottingham University Press, Nottingham, UK. 1997.

(17) Marrero Y., Galindo J., Torres V., Rodríguez Z., Álvarez E., Aldana A.I. et al. Avances en el estudio de las levaduras como activadoras de la fermentación ruminal en bovinos que consumen dietas fibrosas. Revista de Ciencia y Tecnología de la UACJ, 2008; 6: 93.

(18) Carro M.D. \& Ranilla M.J. Los aditivos antibióticos promotores del crecimiento de los animales: situación actual y posibles alternativas, 2002. Disponible en: www.exopol.com.
(19) Agarwal N., Kamra D.E., Chatterjee P.N., Kumar R. \& Chaudhary L.C. In vitro methanogenesis, microbial profile and fermentation of green forages with buffalo rumen liquor as influenced by 2 bromoethanesulphonic acid. Asian Austr. J. Anim. Sci., 2008; 21: 818.

(20) González N. Evaluación de morera (Morus alba Lin) en la fermentación y control de la metanogénesis ruminal de búfalos de río (Bubalus bubalis). Tesis de Doctorado. Instituto de Ciencia Animal, Mayabeque, Cuba. 2010.

(21) Galindo J., González N. \& Delgado D. Los árboles como controladores de los metanógenos y producción de metano en el rumen. II Taller Internacional Salud y Producción Animal-II Congreso Cubano de Desarrollo Local. Granma, Cuba. 2009.

(22) Joblin K.N. Methanogenic Archaea. En: I Planning Meeting of Project Contract Research and Training Workshop "Development and Use of Rumen Molecular Techniques for Predicting and Enhancing Productivity". Brisbane. 2004.

(23) Makkar H.P.S. In vitro gas method for evaluation of feed containing phychemicals. Anim. Feed. Sci. Technol, 2005; 123: 291.

(24) Galindo J., González N., Scull I., Marrero Y., Sosa A., Aldana A.I. et al. Effect of Samanea saman, (Jacq.) Merr, Albizia lebbeck Benth and Tithonia diversifolia (Hemsl.) Gray (plant material 23) on the methanogen population and on the ruminal microbial ecology. Cuban J. Agric. Sci., 2012; 46: 273. 